\title{
Development of Cupcake Production Technology Using Rye Flour
}

\author{
N.G. Hovhannisyan, A.P. Vanoyan \\ Armenian National Agrarian University \\ narinehovhannisyan1984@mail.ru, vanoyananush@mail.ru
}

\section{A R T I C L E I N F O}

\section{Keywords:}

confectionery,

production,

rye flour,

functional food,

improver

\begin{abstract}
A B S T RA C T
Functional food production has become relevant, particularly in recent years, related to technical advancement, reduction of physiological energy consumption and imbalance in labor capacity. Healthy diet is one of the most important factors describing the health of country's population.

In this regard development of new technologies for manufacturing new range of flour confectionery products is considered to be quite actual, while functional food production technology is of significant importance from the prospect of food industry development on the whole.
\end{abstract}

The recommended technology can be easily introduced in the production with no need for additional technological equipment.

\section{Introduction}

Healthy, balanced and full diet is the guarantee for human growth and development, as well as for the prevention of various diseases and health protection. Functional food consumer properties include three components: nutritional value, flavor quality, physiological effect. Traditional foods, in contrast to the functional ones, are characterized only by the first two components (Matveeva and Koryachkina, 2012, Glenn and Christine, 2000).

One of the primary directions for the development of confectionery production sector is the development of new range of products using new raw materials. Flour confectionery has high nutritional value, quite attractive appearance and taste, but they contain large amount of fats, sugars and carbohydrates, while very small amount of other useful nutrients.

Confectionery specialists around the world are developing, improving and producing new confectionery products useful for children and older people. They mainly contain alternative raw materials that have significant amount of functional food components. However, on the other hand, there are many useful components and raw materials that are sometimes impossible to apply in processing technologies meanwhile ensuring food attractiveness for consumers (Matveeva, 2012).

Cupcakes are products made of sweet yeast dough, which contain large amount of eggs, sugar and fats, while for taste property improvement they are also supplemented 
with raisins, fruits, succades, nuts, etc. Anyhow, they don't contain any functional component (Tikhomirova, 2002).

The bakery flour made from rye flour is the second to wheat flour in the production and consumption sector. It contains iron, one and half times more magnesium $(32.0 \mathrm{mg})$ than wheat flour, $224.0 \mathrm{mg}$ potassium, as well as vitamins $\mathrm{B}_{2}$, $B_{3}(P P), B_{3}(P P), B_{4}, B_{5}, B_{6}$ and $\mathrm{B}_{9}$ (Kuznetsova, 2014).

Another important factor is the high fiber content $(8.0 \mathrm{mg})$, which has rather beneficial effect on human digestion. The rye fibers are somewhat unique, as they rapidly get mingled with water molecules, which means that they are able to bind and remove toxins and harmful substances accumulated in the body. Though the rye flour has other considerably useful properties, it hasn't found wide application in confectionery production yet, since up to now no high quality product has been manufactured due to shortcomings in technological processes. (Kuznetsova, 2014, Matveeva, 2012).

\section{Materials and methods}

The control sample of cupcake product, product types prepared via different ratios of rye flour, as well as those made with supplemental "HIT" improver have served as research materials.

Taking into account the urgency of developing new technologies for healthy food production and the relevance of expanding such products range, an objective was set up to produce a wide range of cupcake products with high nutritional value by applying high portion of rye flour, as well as to ensure the proper structural-mechanical properties and quality improvement indices of the mentioned products.

While paving paths for the accomplishment of the mentioned objective the following steps should be tracked out:

- developing a new technology and recipe for producing new cupcake product as a flour confectionery by applying possibly less nutritional ingredients and high portion of rye flour,

- investigating the qualitative properties of cupcake, particularly structural-mechanical and physicochemical indicators,

- identifying the interrelations between the aerated (whip) mass and dough density per the applied flour portion,

- estimating the optimal portion of rye flour and the opportunities of using the improver.
While evaluating the qualitative indicators of the finished product, the common research methods regulated through the GOST standards have been used. The research was conducted in line with the technical requirements set upon GOST 15052-2014. It should be noted that this standard is common for cupcake production (GOST 15052-2014).

In the result of the experimental research, it has been proved that as a high nutritional value product, considerable portions of rye flour can be used in flour confectionery production ensuring proper structural and mechanical indices in the finished product.

\section{Results and discussions}

While developing a new recipe for the cupcake product type, the density of the finished product has been studied, as it is considered to be one of the important indicators for this product.

During the research, two different methods for making cupcakes from the rye flour were considered: upon the first method only some portion of rye flour has been used, while in the second method the universal improver has been also used as a supplement together with the rye flour. For the control variant a cupcake was prepared with $100 \%$ high quality wheat flour, $15.0 \%$ egg products, $35.0 \%$ sugar, $50 \%$ margarine, $1 \%$ emulsifier, $1 \%$ baking powder per the flour mass.

In experimental samples, rye flour substituted the high quality wheat flour with fluctuating portions (25\%, $35 \%$ and $55 \%$ ). In the result of investigations conducted within the frame of the first method, it has been found out (Figure 1) that along with the increase of rye flower amount, the dough density also grew up, which resulted in the reduction of specific volume of the finished product.

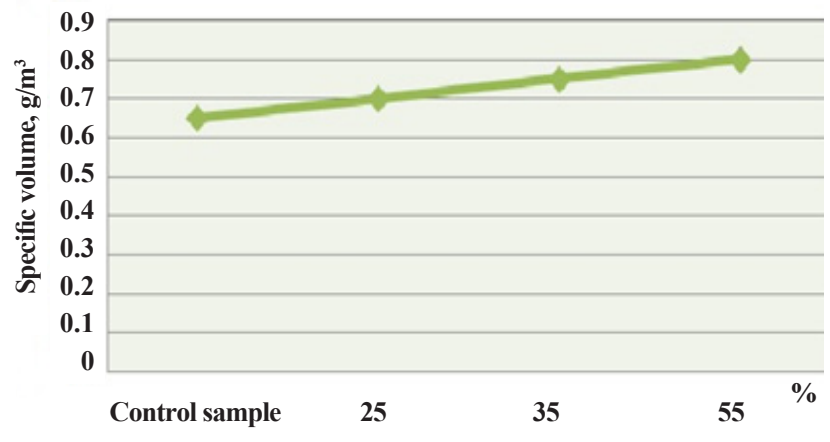

Figure 1. Content of rye flour (composed by the authors). 
To reduce the density of the dough, we studied the opportunity of replacing the margarine with vegetable oil per fat content estimation. It has been disclosed that practically the dough density and the specific volume of the sample weren't subjected to any changes, which enabled to substitute the wheat flour with rye flour in the cupcake recipe. Nevertheless, final marketable appearance of the product was not ensured.

As it is shown in the diagram the density of the finished product in the control sample made $0.65 \mathrm{~g} / \mathrm{m}^{3}$, then, together with the increase of rye flour content it gradually amounted up to $0.80 \mathrm{~g} / \mathrm{m}^{3}$, which is a desirable indicator for this product type.

The study was also carried out for the cupcake product made via improver application. Since the optimal application dosage of this improver in the bread products manufacture is $0.1-0.5 \%$ per $100 \mathrm{~kg}$ of wheat flour and it hasn't been used in the confectionery production before, we have chosen the dosage of $0.1 \%$ per the flour mass. In this case again, rye flour with fluctuating contents $(25 \%$, $35 \%$ and $55 \%$ ) was applied instead of wheat flour.

Like in the first case, here again, the product density was first examined.

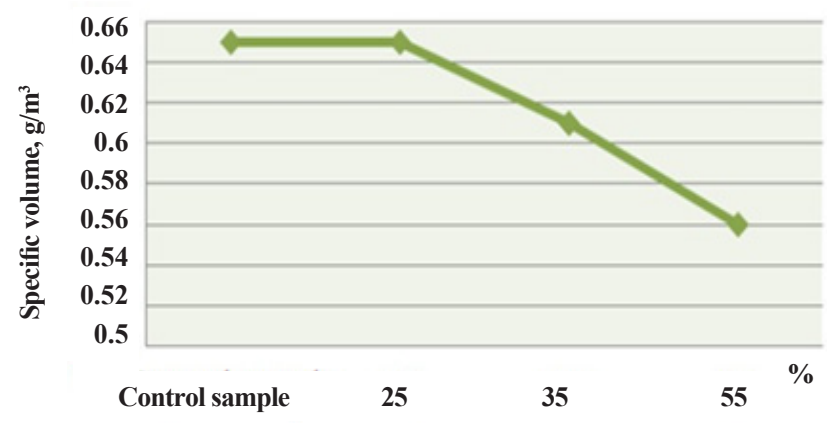

Figure 2. Content of rye flour, \% (composed by the authors).

As it is shown in Figure 2, when using $0.1 \%$ "HIT" improver the density of product underwent slight changes: from $0.65 \mathrm{~g} / \mathrm{m}^{3}$ to $0.56 \mathrm{~g} / \mathrm{m}^{3}$, which enabled to obtain high volume products.

Usually cupcake products are baked immediately after preparing the dough, i.e. for such products there is no maturation process planned upon the technology. However, given the fact that there is a baking improver (powder) in the experimental sample, the dough has also been maturated when performing the experiment. The impact of the improver on the duration of the fermentation has been studied. It turned out (Table) that the cupcake differed in volume, smooth top and high porosity when the dough was maturated for 90 minutes, which is not typical to those cupcakes produced through traditional recipes.

Table. The impact of dough maturation on the quality of cupcakes*

\begin{tabular}{|c|c|c|c|c|}
\hline \multirow{2}{*}{ Indicator } & \multicolumn{4}{|c|}{ Maturation duration, $\mathbf{m}$} \\
\hline & 30 & 60 & 90 & 120 \\
\hline Specific volume, $\mathrm{cm}^{3} / \mathrm{g}$ & 1.5 & 1.6 & 2.1 & 1.5 \\
\hline $\begin{array}{l}\text { Compressibility, } \\
\text { scale point }\end{array}$ & 13.0 & 15.0 & 17.2 & 16.2 \\
\hline Acidity degree & 1.6 & 1.9 & 2.3 & 2.6 \\
\hline Humidity, \% & 18.1 & 18.8 & 20.1 & 22.3 \\
\hline Crumbiness, $\%$ & 47.4 & 50.1 & 53.2 & 55.6 \\
\hline
\end{tabular}

The best physicochemical indicators of the finished products were observed in case of 60-90 minutes of dough maturation in experimental samples, which intensified gas generation process and, hence, the dough mass significantly increased in size; nevertheless, after baking it was characterized with smooth top and high porosity, and therefore did not meet the overall requirements of the product.

\section{Conclusion}

As a result of experimental studies it was concluded that in the cupcake production process, wheat flour may be replaced with $55 \%$ rye flour content. It has been also proved that the use of improver in the rye flour cupcakes can provide relevant structural and mechanical properties of the finished product.

The research results have also indicated that the use of the bread baking improver has a positive effect on the structural indicators of cupcakes; particularly, the density of the cupcakes dough is reduced, as a result of which high quality products are obtained.

In case of improver application, an increase in the products specific volume has been recorded: from $1.5 \mathrm{~cm}^{3} / \mathrm{g}$ 
up to $2.1 \mathrm{~cm}^{3} / \mathrm{g}$, which could not be ensured in case of using only rye flour.

It has been also proved that the dosage of $0.1 \%$ improver is an effective quantity, and as an additional raw material it won't affect the further cost price of the product.

Thus, the developed technology can be introduced in the production with no need for additional technological equipment and facilities.

\section{References}

1. Glenn, R. Gibson, Christine, M. Williams. (2000). Functional Foods: Concept to Product (Woodhead Publishing Series in Food Science, Technology and Nutrition), - pp. 11-16.
2. GOST 15052-2014 CUPCAKES. General Technical Conditions -2014 .

3. Kuznetsova, L.I. (2014). The Use of Rye Flour in the Technology of Cupcakes / L.I. Kuznetsova, E.M. Surmach // Bulletin of HEIs. Food Technology, - N 1, - pp. 60-61.

4. Matveeva, T.V., Koryachkina, S.Ya. (2012). Monograph: Physiologically Functional Food Ingredients for Bakery and Confectionery Products: Orel - State Federal Budgetary Educational Institution for Higher Professional Education "State University - Educational - Scientific - Production Complex", - 947 p.

5. Tikhomirova, N.A. (2002). Technology of Functional Food Products. Moscow: LLC "Frantera", - 213 p. 